\title{
Divide over treating opioid-addicted moms
}

A program in northern Ontario to treat pregnant women addicted to opioids, was launched just one week after Tennessee took a very different approach to the epidemic of opioid-addicted babies: it passed a law to imprison new mothers for drug use.

Under the law, women whose babies are born addicted to or considered harmed by illicit drugs will be charged with misdemeanor assault, which carries a sentence of up to one year in jail. According to the Tennessee Medical Association, 855 babies were born addicted to opioids in the state last year and needed in-hospital morphine-tapering treatment at an average cost of $\$ 70000$ per child.

Laws punishing pregnant women have been widely condemned by addictions experts, women's rights advocates and the medical community, including the American Medical Association and American College of Obstetricians and Gynecologists.

"It will drive women underground," says Dr. Jacquelyn Starer, an obstetrician and president of the Massachusetts Society of Addiction Medicine.

Although the law stipulates that women who complete treatment can use that as a defence if they're charged, they would still face arrest and a judge might not agree with the defence, says legal expert Lynn Paltrow, the executive director of National Advocates for Pregnant Women. Meanwhile, Starer notes that most people who are addicted to opioids remain on methadone therapy for life. "There really is no such thing of completing treatment."

Furthermore, Starer is concerned that the threat of persecution would cause women to try to stop drugs on their own, leading to sharp variability in dosage, which can cause fetal hypoxia and fetal death.

Cherisse Scott, founder and CEO of SisterReach, a reproductive rights organization based in Memphis, echoes Starer's concerns. "We're really afraid

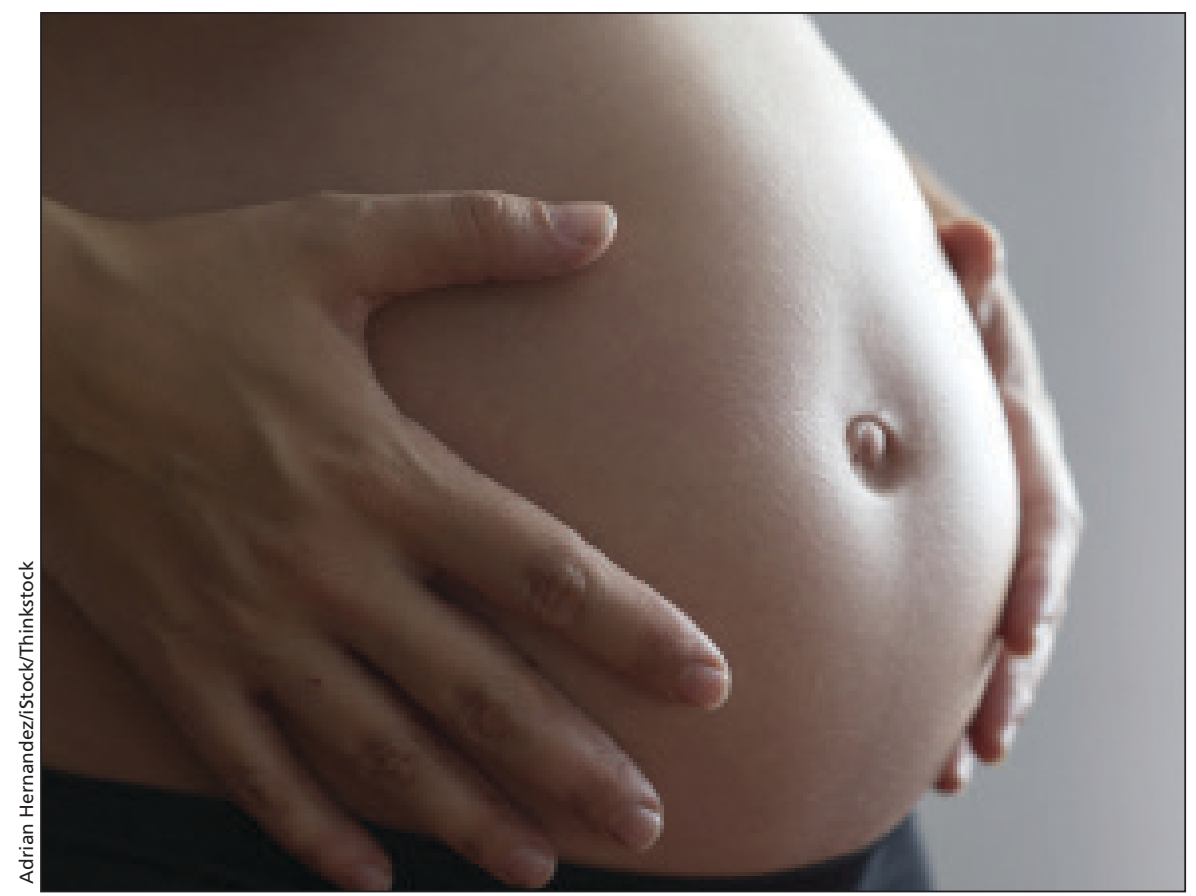

Laws punishing pregnant women for their addictions have been widely condemned by addictions experts, women's rights advocates and the medical community.

it's going to force women to make decisions around their reproductive health like foregoing prenatal care, or getting abortions to avoid being policed by doctors." She adds that the law will "disproportionately impact poor women and women of colour."

A spokesperson for Tennessee Governor Bill Haslam, who passed the law, said the governor was referring media to the law's sponsors, Senator Reginald Tate and State Representative Terri Lynn Weaver. Neither responded to repeated interview requests.

\section{Opposing approaches}

The Tennessee approach differs dramatically from one being taken in Thunder Bay, Ontario, where opiate usage among indigenous communities is reaching alarming rates. Dr. Cheryl Everall, medical director of a new methadone program for pregnant women, said 300 pregnant women test positive for opiate use in the city of 110000 each year.

The program enrols women on methadone through their primary care provider. In fly-in communities where a doctor isn't available, suboxone is used instead. The methadone dosage is adjusted at various points to take into account that women metabolize drugs differently depending on their stage of pregnancy, notes Everall. Women are also provided or referred for counselling, as well as social support programs.

"Up to $80 \%$ of patients with a diagnosis of opioid dependence also fulfill criteria for other psychiatric issues, like posttraumatic stress disorder, depression, and anxiety," says Everall, Some of her patients were prescribed opiates following an injury and were unable to discontinue them, while others were exposed to them recreationally.

The Tennessee law "trivializes opioid dependence down to a phenomenon that can be willed away," says Everall, noting that addiction is as much a physical illness as a mental issue.

\section{Tennessee MDs}

Although the president of the Tennessee Medical Association has expressed 
serious concerns about the law there, Paltrow argues that the association "collaborated in the design of laws that criminalize their patients" by suggesting amendments to the law rather than demanding it be scrapped altogether.

The association recommended three changes: reducing the maximum charge from felony (with a 15-year term) to misdemeanor; allowing prebirth treatment enrolment as grounds for defence; and making the law temporary so that its effect can be evaluated. The amendments were all included and the law expires on June 30, 2016.

Yarnell Beatty, vice president of advocacy for the Tennessee Medical Association, explained his organization's response in an email. He wrote that drug courts provide a path to the only publicly funded addiction treatment for many women in the state. (A judge can demand a woman enrol in treatment to avoid a jail sentence.) $\mathrm{He}$ said the association initially opposed the bill but "had to shift to lessening the sting of it on pregnant patients once it was apparent that drug courts could actually be part of the solution to the treatment dilemma." — Wendy Glauser, Toronto, Ont.

CMAJ 2014. DOI:10.1503/cmaj.109-4813 